\title{
O papel dos Sistemas e Cadeias Agroalimentares e Agroindustriais na formação das aglomerações produtivas dos territórios rurais
}

\author{
Jorge Luiz Amaral de Moraes ${ }^{1}$
}

\section{Resumo}

As transformações nos processos produtivos locais deram origem a novas dinâmicas de desenvolvimento. Assim, tornaram-se necessários novos instrumentos de ações do Estado e políticas públicas de desenvolvimento das aglomerações produtivas e dos sistemas e cadeias agroalimentares e agroindustriais. Teve início um novo impulso nos estudos que utilizam abordagens teóricas que podem explicar a gênese e o funcionamento das atuais dinâmicas de desenvolvimento dos territórios, dando origem à perspectiva territorial do desenvolvimento e à abordagem dos Sistemas Produtivos Localizados (SPLs). As teorias do desenvolvimento regional e rural passaram a considerar a dinâmica dos territórios rurais, superando a dicotomia ruralurbano e utilizando uma perspectiva multisetorial e territorial do desenvolvimento rural. A partir de uma análise da dinâmica socioeconômica do desenvolvimento dos territórios rurais, utiliza-se a abordagem teórica dos Sistemas Produtivos Agroalimentares Localizados (SIALs). Foram analisados aspectos teóricos relacionados à gestão de sistemas e cadeias produtivas agroalimentares e agroindustriais, como estruturas produtivas básicas dos SIALs. Utilizou-se conceitos teóricos e abordagens adequados para compreender as estruturas e o funcionamento dos sistemas e cadeias produtivas agroalimentares e agroindustriais. Verificam-se relações entre o desempenho de sistemas e cadeias produtivas e o desenvolvimento regional. Destaca-se a importância do conhecimento das estruturas e do funcionamento dos sistemas e cadeias agroalimentares e agroindustriais para o planejamento e gestão do desenvolvimento regional-local.

Palavras-chave: Sistemas Agroalimentares Localizados. SIALs. Sistemas agroalimentares. Aglomerações produtivas. Territórios rurais.

\begin{abstract}
The changes in production processes given rise to new local dynamics of development and it became necessary new tools for state actions and policies of development of productive clusters and systems and chains agrifood and agroindustrial. Started a new impetus to studies using theoretical approaches that

1 Engenheiro Agrônomo. Doutor em Desenvolvimento Rural. Professor do Departamento de Economia da Universidade de Santa Cruz do Sul - UNISC/RS e do Programa de Pós-Graduação em Desenvolvimento Regional das Faculdades Integradas de Taquara - FACCAT/RS. imoraes12@gmail.com
\end{abstract}


can explain the genesis and the functioning of the current dynamics of development of territories, giving rise to the territorial perspective of development and the approache of Localized Productive Systems (SPLS). The theories of regional and rural development have begun to consider the dynamics of rural territories, overcoming the rural-urban dichotomy and using a multisectoral approach and territorial-rural development. In analysis of the dynamics of the socioeconomic development of rural territories we use the theoretical approach of Localized Agrifood Systems (SIALS). Was analyzed the theoretical aspects related to management of the systems and chain agrifood and agroindustrial, which are the basic productive structures of the SIALs. Were used some theoretical concepts and approaches that, increasingly, have proved suitable for studying and understanding of the structures and functioning of agrifood and agroindustrial systems and chains. Proved to be some associations between regional development and performance of these chains, the importance of knowledge about the structure and functioning of these systems and chains, and for planning and managing of regional-local development.

Keywords: Localized Agrifood Systems. SIALs. Rural territories. Agrifood systems. Agroindustrial chains.

\section{Introdução}

Com o aprofundamento do processo de globalização dos mercados e da produção, aumentou também a competitividade decorrente de uma expansão da escala de produção das indústrias, quando as empresas transnacionais procuram organizar a sua logística dentro de um padrão operacional global.

Esse contexto tem gerado a necessidade de novas formas de atuação e organização dos atores sociais locais e das empresas, privadas e cooperativas, de ações institucionais e de uma perspectiva territorial para estudar os processos de desenvolvimento regional em curso. Essas mudanças vêm acontecendo a partir das diversificações horizontais, quando ocorrem formações de redes, alianças, fusões e aquisições, e das diversificações verticais, quando há investimentos nos sistemas e cadeias produtivas e nas estruturas de distribuição.

Com isso, teve início um processo de reestruturação do sistema produtivo capitalista, reorganização da produção globalizada e, desde o final dos anos 60 , mudanças no modo de regulação fordista do perído pós-guerra. Essa reestruturação vem provocando significativas mudanças nos processos locais e territoriais de produção e consumo e aprofundando os desequilíbrios regionais. Esse movimento 
vem gerando novas demandas e formas de políticas públicas para o desenvolvimento dos territórios. Estes, por meio de seus atores locais, tentam responder aos efeitos da globalização, ao mesmo tempo em que passam a fazer parte, de forma mais ativa, da trajetória da reestruturação do sistema produtivo global através de modificações, adaptações e a formação de novos sistemas produtivos locais. Por isso, já se verificam novas dinâmicas locais de desenvolvimento, em resposta aos efeitos da globalização e da reestruturação produtiva global sobre os sistemas produtivos locais.

As transformações nos processos produtivos locais e os seus resultados nas diferentes regiões, associadas às características físicas, político-culturais e socioeconômicas internas de cada território, deram origem a diversificadas dinâmicas de desenvolvimento local com trajetórias bastante diferenciadas e complexas. A falta de conhecimentos sobre essas dinâmicas socioeconômicas locais tornou-se um importante limitador do alcance dos instrumentos e políticas públicas e privadas de desenvolvimento e das ações do Estado como agente indutor eficaz desse desenvolvimento das aglomerações produtivas e, particularmente, dos sistemas e cadeias agroalimentares e agroindustriais.

Como resultado, emergiu a necessidade de mudanças nas formas de interpretação das teorias e políticas de desenvolvimento regional, abandonando-se os paradigmas que pretendiam explicar os desequilíbrios regionais a partir apenas da reorganização da produção globalizada. Isso deu um novo impulso aos estudos que utilizam abordagens teóricas que, após uma necessária constatação empírica, pudessem explicar a gênese e o funcionamento das atuais dinâmicas de desenvolvimento dos territórios.

Os resultados dos estudos sobre reestruturação produtiva, desenvolvimento regional e aglomerações produtivas territoriais deram origem à perspectiva territorial do desenvolvimento. Dessa perspectiva surgiram as abordagens dos Clusters ou Arranjos Produtivos Locais (APLs), dos Sistemas Produtivos Localizados (SPLs) e dos distritos industriais, agroindustriais e agrícolas. Mais recentemente, as teorias do desenvolvimento regional e rural passaram a considerar a dinâmica territorial, superando a dicotomia rural-urbano, utilizando uma perspectiva multisetorial e 
territorial do desenvolvimento, a partir de uma análise da dinâmica socioeconômica do desenvolvimento dos territórios rurais, com uma abordagem teórica apoiada nos Sistemas Agroalimentares Localizados (SIALs).

Além desta introdução, este texto conta com mais quatro seções. A seguir, serão apresentados alguns dos efeitos da restruturação produtiva mundial sobre os territórios e a formação das aglomerações produtivas locais, como os Sistemas Produtivos Localizados (SPLs). Em seguida, descrevem-se os processos resultantes da integração da agricultura com os setores industrial e de serviços e a consequente formação dos sistemas e cadeias agroalimentares e agroindustriais, incluindo conceitos e algumas formas de gestão dessas estruturas de suporte das aglomerações produtivas agroalimentares e agroindustriais. Na penúltima seção, serão apresentadas algumas características dos processos de formação de algumas aglomerações produtivas dos territórios rurais, como dos distritos "agrícolas" e "agroindustriais" italianos e dos Sistemas Agroalimentares Localizados (SIALs). Ultimando, apresentam-se as considerações finais.

\section{Os territórios e a formação das aglomerações produtivas locais}

Com a atual crise do modelo produtivo mundial e a flexibilização geral (organizacional e das relações de trabalho) do capitalismo, emerge um novo sistema de regulação socioeconômica e política, na qual um grande conjunto de pequenas e médias empresas vem garantindo a diversificação e um aumento na participação da produção. Com isso, cresceu a importância da produção flexível, da inovação tecnológica e das vantagens competitivas das aglomerações produtivas locais.

A evolução das novas relações nas sociedades contemporâneas demonstra empiricamente e valida os conceitos e definições que enfatizam a relação dialética entre as esferas local e global. As relações sociais locais são reflexos dos fatos e das ações dos atores globais, enquanto estas são também consequências das relações e ações locais. O global não existe sem o local, mas, em grande parte, este se caracteriza pelas relações socioeconômicas estruturadas pelas relações 
socioeconômicas e políticas globais. Como há necessidade de se buscar um equilíbrio entre o global e o local, o foco não pode ser apenas nas relações com o exterior, mas também nas relações e interações internas dos territórios. Nesse caso, o local reage e responde aos estímulos provocados pelas ações dos atores globais. Esse contexto caracteriza o que vem sendo denominado de Desenvolvimento Territorial (MORAES, 2008).

$\mathrm{Na}$ esteira do debate em torno dos caminhos da reestruturação produtiva capitalista, desde o início da década de 1980, intensificaram-se os estudos que utilizam as abordagens "locais", "endógenas" e, mais recentemente, "territoriais" do desenvolvimento (BENKO, 2002; BENKO; LIPIETZ, 1994; REIS, 2006; SABOURIN, 2002). Assim, diversos estudos, como o de Reis (2006), passaram a dar mais ênfase aos fatores endógenos, à ação dos atores sociais locais, à dimensão territorial, ao papel das instituições e às aglomerações produtivas locais nos processos de desenvolvimento.

Como resultado da relação da sociedade com o seu espaço, o conceito de território destaca as relações da sociedade local com as suas atividades econômicas e produtivas. Para que se tenha um território é necessário que a sociedade ou grupos sociais apropriem-se do espaço físico, que se ampliem e se utilizem as inovações tecnológicas e que exista um sentimento de pertencimento ou a identificação da sociedade com o seu território.

As dinâmicas socioeconômicas de desenvolvimento de um território, região ou conjunto de municípios são condicionadas pela organização local do seu sistema de produção. Esses sistemas são formados pelas interações entre as empresas locais, propiciando economias de escala, de escopo, de proximidade ou de aglomeração. Essas geram vários mercados internos e áreas de contato com o exterior, facilitando as trocas de informações e conhecimentos e outros bens e serviços. Diferentemente do crescimento industrial verificado até o final dos anos 1970, os resultados de uma ampla variedade de estudos indicam uma crescente importância atribuída aos territórios e às aglomerações produtivas locais e o aparecimento de novas formas de segmentação dessas (MORAES, 2008). 
Uma aglomeração produtiva é a concentração de atividades similares ou interdependentes em um determinado espaço ou território, não importando o tamanho das empresas, nem a natureza da atividade econômica desenvolvida. Essas atividades podem pertencer ao setor agrícola, industrial ou de serviços. Pode incluir desde estruturas artesanais, com pequeno dinamismo, até arranjos que comportem uma grande divisão de trabalho entre as empresas. Geralmente, os produtos resultantes têm um elevado conteúdo tecnológico. Dentro do aglomerado, a divisão do trabalho entre as empresas permite que o processo produtivo ganhe flexibilidade e eficiência, já que as empresas são obrigadas a se tornarem competitivas nas suas atividades. A concentração de produtores especializados estimula o desdobramento da cadeia produtiva a montante, principalmente pelo surgimento de fornecedores de matérias-primas, máquinas e equipamentos, peças de reposição e assistência técnica, além de serviços especializados. Essa concentração estimula também o desenvolvimento da cadeia produtiva a jusante, por meio da atração de empresas especializadas nestes segmentos e do surgimento de agentes comerciais que levam os produtos para mercados distantes (REIS, 1992).

Assim, emerge um debate em torno da formação e do papel das aglomerações produtivas locais ou localizadas, resultando nas abordagens teóricas dos "Arranjos Produtivos Locais (APLs)", dos "Sistemas Produtivos Localizados (SPLs)" e dos "Sistemas Agroalimentares Localizados (SIALs)". Esses SIALs são estruturados a partir dos sistemas (SAGs) e das cadeias produtivas (CPA) agroalimentares e agroindustriais presentes nos territórios rurais. Acredita-se que essas abordagens, além de contribuírem para fornecer algumas pistas para as questões do desenvolvimento local, possam também servir de base para políticas e instrumentos de produção e desenvolvimento de sistemas e cadeias agroalimentares e agroindustriais, mais ajustados ao perfil específico de cada território rural e de suas potencialidades locais.

Algumas indicações sobre as origens dos estudos sobre os territórios, SPLs, APLs podem ser encontradas nas abordagens teóricas que tratam da concentração espacial de empresas e das principais tipologias dos aglomerados produtivos. Como essas têm implicações diretas na formulação de políticas industriais, podem 
contribuir também para as políticas de desenvolvimento de uma determinada região ou território.

Assim, muda o enfoque que percebe a empresa como uma unidade autônoma para outro, em que a empresa passa a ser analisada como parte do ambiente socioeconômico e físico, ao qual ela pertence. Esse é o ambiente socioterritorial onde ocorre o processo produtivo que, consequentemente, transforma-se em uma nova unidade de produção e análise.

Nesse contexto, os Sistemas Produtivos Localizados (SPLS) e, particularmente, os Sistemas Agroalimentares Localizados (SIALS), nos territórios rurais, aparecem como mecanismo de mediação entre os efeitos da globalização e as dinâmicas socioeconômicas locais de desenvolvimento dos territórios, através da coordenação, aproveitando as oportunidades externas e as potencialidades endógenas desses territórios. Estes, então, passam a ser representados pelas suas dinâmicas locais de desenvolvimento e tomam a forma de SPLs e SIALs. Assim, os territórios podem ser analisados sob o ponto de vista organizacional, produtivo, social, institucional e de suas articulações externas e internas. A partir desse mecanismo, atores e instituições passam a gerenciar a produção e os recursos endógenos, executando ações de coordenação do território e de suas aglomerações produtivas.

\subsection{Os Sistemas Produtivos Localizados (SPLs)}

Os estudos sobre os Sistemas Produtivos Localizados (SPLs) têm origem nos trabalhos de Alfred Marshall, ainda no final do século XIX, sobre a organização da produção, identificando a formação dos "distritos industriais". Esses estudos serviram de ponto de partida para o surgimento de um leque de variantes a partir do conceito de distrito industrial, que buscam identificar e classificar a formação de aglomerações produtivas.

Marshall destacava a localização das indústrias como fator gerador de diversas vantagens para a população local dos territórios, tais como a transmissão quase espontânea dos conhecimentos do ofício de uma geração a outra, o desenvolvimento de tecnologias inovadoras relativas ao ofício e à transmissão das formas de organização do negócio entre os atores, as facilidades geradas pela 
concentração de mão de obra especializada, para os trabalhadores encontrarem trabalho e para as empresas encontrarem mão deobra de boa qualidade e 0 aumento da concorrência de fornecedores e de serviços associados, favorecido pela concentração das indústrias, o que diminui os custos de produção das empresas (MARSHALL, 1992).

A abordagem dos SPLs tanto pode englobar uma cadeia produtiva estruturada localmente como seconcentrar em um ou mais segmentos de uma cadeia produtiva específica de abrangência nacional e/ou internacional. Entre os atores que atuam nos SPLs, incluem-se, entre outros, o Estado, empresas produtoras, fornecedoras de insumos, financeiras e prestadoras de serviços, associações de classe, associações comerciais, instituições de suporte, serviços, fomento, ensino e pesquisa (POMMIER, 2002).

No Brasil, a Rede de Pesquisa em Sistemas Produtivos e Inovativos Locais (Redesist), coordenada pelo Instituto de Economia da Universidade Federal do Rio de Janeiro (CASSIOLATO; LASTRES, 2002) define Arranjo Produtivo Local (APL) como um aglomerado de agentes econômicos, políticos e sociais, localizados em um mesmo território, que apresentam fortes vínculos de articulação, interação, cooperação e aprendizagem. Uma das principais vantagens dos estudos focados nos SPLs e APLs, segundo Cassiolato \& Lastres (2003), é o fato de esses representarem uma unidade prática de investigação que vai além da tradicional visão baseada na empresa, no setor ou somente em uma cadeia produtiva. Assim, permite-se estabelecer uma ponte entre o território e as atividades econômicas; focalizar um grupo diversificado, tanto de agentes ligados diretamente à produção como de atividades conexas (principal característica de um sistema produtivo e inovativo local); representar o território a partir de um espaço no qual são oferecidas as condições para a inovação; representar um importante desdobramento da implementação de políticas de desenvolvimento.

Atualmente, entende-se que os SPLs representam os mecanismos de mediação entre os efeitos do capitalismo global e as propostas locais-endógenas para o desenvolvimento territorial, por meio da coordenação e negociação. 
A definição de SPL destaca a forma de organização, o processo de desenvolvimento local e o papel dos atores e instituições dentro do sistema. Enquanto o desenvolvimento local corresponde à dimensão social do SPLs, implicando melhores condições de vida, a forma de organização corresponde a processos históricos de consolidação sobre um espaço físico de uma população que desenvolve relações culturais e de identidade com o território, além da localização das indústrias em um determinado espaço geográfico (CORREA, 2004).

Desde o início da década de 1970, os sistemas produtivos locais (SPLs) de diversos territórios do Brasil vêm caminhando para uma crescente articulação ou integração socioeconômica com setores capitalistas mundiais, por intermédio de cadeias globais de produção e consumo. Essa articulação e/ou integração tem sido o caminho seguido por algumas regiões ou territórios como respostas locais às mudanças provocadas pela reestruturação do sistema produtivo global e à modernização tecnológica dos processos produtivos (MORAES, 2008).

\subsection{O Setor agroalimentar e as cadeias globais de produção e consumo}

Bonanno (1999) cita William H. Friedland como autor de uma alternativa crítica importante aos pressupostos das teorias da pauta dos debates sobre a evolução dos sistemas agroalimentares e agroindustriais globais e o fim do fordismo. A proposta de Friedland, na segunda metade da década de 1990, reconhece tanto a natureza contraditória da evolução da economia global como a ação das diferentes classes sociais envolvidas nesse processo e vê a globalização como um fenômeno desigual que não afeta da mesma forma e com a mesma abrangência todas as regiões, setores e mercadorias. Embora reconhecendo que as tendências para a especialização e a globalização da produção tenham sido confirmadas, Friedland afirma que essas tendências não são caracterizadas pela produção artesanal. Ele cita como exemplo o caso da produção de frutas e vegetais in natura na Holanda, onde a presença de pequenas unidades familiares de produção e a descentralização de um amplo sistema de integração vertical não representa o fim da "produção em massa" e a emergência de um sistema manufatureiro baseado na forma artesanal. Segundo ele, indica o desenvolvimento de um sistema de produção em massa bem 
mais sofisticado (talvez mais apropriado fosse chamar de um "neofordismo"), que está ancorado nas pequenas unidades familiares de produção Essas pequenas unidades não podem ser consideradas independentes, porque são controladas pelas grandes corporações transnacionais, que empregaram esquemas técnicos e legais para fragmentarem o poder de barganha das unidades de produção. Esse parece ser um caso semelhante ao que acontece na produção de tabaco no sul do Brasil.

Para Friedland, a formação de nichos de mercado é o tópico principal para se entender a produção em massa individualizada, pois esse fenômeno é a fragmentação de um mercado de massa-padrão em uma variedade de mercados com produtos especializados. Isso responde à crise nos mercados homogêneos de massa, pois introduz um sortimento de produtos necessários para o atendimento das novas demandas dos consumidores globais. Na essência, apesar da aparente independência dos produtores, o processo de trabalho e os produtos mantêm seu caráter fordista e continuam totalmente controlados por aqueles setores que estão "acima" dos produtores. Foi a teoria dos nichos de mercado que permitiu a Friedland rejeitar as teses do fim do fordismo e a transição para um pós-fordismo.

No entanto, no debate brasileiro em torno do desenvolvimento rural, já se identifica uma mudança de visão nas novas abordagens utilizadas para compreender o papel do mundo rural no desenvolvimento do país. Uma nova perspectiva de estudo vem substituindo a visão tradicional, que se apoiava na dicotomia rural-urbana e via o rural como sinônimo de agrícola, por uma visão sobre o mundo rural baseada na possibilidade desse "território rural" incluir, também, as pequenas cidades do "interior" e oferecer novas alternativas de emprego e renda e diversas outras formas de melhoria na qualidade de vida da sua população. Esperase que, assim, o território rural possa utilizar o seu potencial local, suas características históricas e culturais e, ao mesmo tempo, as oportunidades externas, levando a uma nova ruralidade e contribuindo para o desenvolvimento desses territórios.

\section{Sistemas e cadeias agroalimentares e agroindustriais}


As regiões rurais estão, cada vez mais, diversificando as suas atividades e trajetórias de desenvolvimento que, nos novos espaços rurais, são coordenadas por diferentes redes (MURDOCH, 2000). Então, destacam-se as significativas interações entre os sistemas e cadeias agroalimentares e agroindustriais e os territórios, decorrentes do fato de que as lógicas das cadeias produtivas e a dos territórios serem inseparáveis (SAUTIER, 2002). Essas interações, que são também relações de interdependência, encarregam-se de explicar as dinâmicas territoriais-locais e as formas específicas de articulação entre o "local" e o "global", uma vez que no espaço local é onde ocorre a convergência entre o rural e o urbano, onde se encontram o "mundo urbano" e o "mundo rural" (WANDERLEY, 2001).

Nos conceitos adotados nas abordagens dos sistemas agroalimentares e agroindustriais (SAGs) e das cadeias produtivas agroalimentares e agroindustriais (CPAs), agribusiness ou agronegócios e, consequentemente, dos Sistemas Agroalimentares Localizados (SIALS), destacam-se os relacionamentos entre a produção agrícola, as empresas agroindustriais e de serviços (fornecedores, processadores e distribuidores) e o ambiente socioeconômico. Essas abordagens interpretativas são formadas por três grandes segmentos, o segmento "antes da porteira", os fornecedores para a agropecuária (ou agricultura), o "dentro da porteira", a produção agropecuária, e os segmentos "depois da porteira", as empresas agroindustriais, as indústrias de alimentos e as distribuidoras do produto final.

3.1 Níveis de análise dos sistemas agroalimentares e agroindustriais

Os professores da Universidade Harvard, Ray Goldberg e John Davis, publicaram, em 1957, o livro A Concept of Agribusiness, que trouxe um novo conceito para a análise da agricultura, saindo da tradicional visão isolada para a análise do sistema que vai desde a produção de insumos até a distribuição, passando pela produção agrícola e agroindustrial. Dessa maneira, a agricultura, em um contexto sistêmico de cadeia produtiva, foi denominada de Agribusiness e definido como: "a soma das operações de produção e distribuição de insumos para a agricultura, das operações de produção nas unidades agrícolas, do armazenamento, 
processamento e distribuição dos produtos agrícolas e itens produzidos a partir delas" (BATALHA, 1997, p. 25).

O Agribusiness ou "Agronegócio" compõe-se de sistemas e cadeias produtivas agroalimentares e agroindustriais que operam em diferentes ecossistemas ou sistemas naturais. No contexto geral do agronegócio, existe um conglomerado de instituições de apoio e coordenação, de organizações de crédito, pesquisa, assistência técnica, entre outras, e um aparato legal e normativo, exercendo forte influência no seu desempenho (DAVIS; GOLDBERG, apud BATALHA, 1997).

Consequentemente, a gestão do agronegócio busca mobilizar conceitos e instrumentos de intervenção nos sistemas e cadeias produtivas, como o crédito agrícola, a inovação tecnológica e gerencial, as normas de taxação, serviços de apoio, entre outros, para melhorar o desempenho em relação a indicadores específicos. Essas intervenções entretanto, só se tornam eficazes quando é possível compreender sistematicamente, o que ocorre todos os segmentos em que a produção agropecuária se insere.

No entanto, o Agribusiness apresenta enfoques metodológicos diferentes. Em 1968, Goldberg publicou outro trabalho onde utilizou a noção de commodity systems approach (CSA), dentro de uma visão sistêmica, tendo como início uma matériaprima básica, conhecido, no Brasil, por Complexo Agroindustrial (CAl). As cadeias de agribusiness são operações organizadas de forma vertical e percorrida pelo produto desde sua produção, elaboração industrial e distribuição, podendo ser coordenadas via mercado, ou por meio da intervenção de agentes diversos ao longo da cadeia, que contribuem ou interferem de alguma maneira no produto final. Essa coordenação pode ter maior importância naquelas cadeias expostas à competição internacional e, especialmente, às crescentes pressões dos clientes, que são os alvos finais das cadeias e a quem estas devem adaptar-se (ZYLBERSTAJN; NEVES, 2000).

A Escola Francesa de Organização Industrial desenvolveu, na década de 1960, o conceito de analyse de filières, que visava analisar parcialmente o agribusiness. Esse modelo foi traduzido para o português como cadeia de produção 
ou cadeia de produção agroindustrial (CPA). Nesse caso, a análise parte do produto final em direção à matéria-prima que the deu origem, diferente do modelo (CSA) proposto anteriormente por Goldberg, que partia de uma matéria-prima básica.

Apesar de terem surgidos em locais e épocas diferentes, as metodologias de análise da cadeia proposta por Goldberg e pela escola francesa (analyse de filières) possuem muitas semelhanças. Por exemplo, as duas utilizam cortes verticais no sistema econômico de um determinado produto/serviço final (mais comum na escola francesa) ou a partir de uma matéria-prima de base, para posteriormente estudar sua lógica de funcionamento. Além disso, ambas dividem o sistema em três subsetores distintos: agricultura, indústria e serviços e partem da premissa que a agricultura deve ser vista dentro de um sistema mais amplo, do qual participam também produtores de insumos, indústria processadora (agroindústrias e indústrias de alimentos) e segmentos de distribuição e comercialização (atacado e varejo).

As duas metodologias de análise apontam nas mesmas direções: estratégia e marketing, política industrial, gestão tecnológica, modelo de delimitação de espaços de análise dentro do sistema produtivo e ferramenta de descrição técnico-econômica de um setor. Os dois conceitos usam a noção de sucessão de etapas produtivas, desde a produção de insumos até o produto acabado, como forma de orientar a construção de suas análises. Ambos destacam o dinamismo do sistema e propõem um caráter prospectivo.

A diferença principal está na importância atribuída ao consumidor final como agente dinamizador da cadeia. A análise de filières privilegia o mercado final (produto acabado/serviço) em direção à matéria-prima básica para a sua produção. Os dois principais aspectos destacados pelas duas metodologias são o caráter mesoanalítico e sistêmico dos estudos de cadeias produtivas agroindustriais (BATALHA, 1997).

Ainda, segundo Batalha (1997), a literatura que trata da problemática agroindustrial no Brasil não tem feito uma boa diferenção entre as expressões "Sistema Agroindustrial", "Complexo Agroindustrial" e "Cadeia de Produção Agroindustrial". Esses conceitos representam espaços de análise diferentes, têm diferentes objetivos e todos foram desenvolvidos como instrumentos de visão 
sistêmica. Parte-se da premissa que a produção de bens e serviços pode ser representada como um sistema, no qual os diversos atores estão interconectados por fluxos de materiais, de capital e de informação, objetivando suprir um mercado consumidor final com os produtos do sistema.

A partir desse ponto do texto, com o objetivo de se tornarem mais abrangentes e práticos, esses termos serão acrescidos da palavra "agroalimentar", ou seja, serão denominados de "Sistema Agroalimentar e Agroindustrial (SAG)", "Complexo Agroalimentar e Agroindustrial (CAI)" e "Cadeia de Produção Agroalimentar e Agroindustrial (CPA)".

Um Sistema Agroalimentar e Agroindustrial (SAG) não está associado a qualquer matéria-prima agropecuária ou produto final específico. Pode-se entender 0 SAG como sendo composto pelos seis conjuntos de atores: (1) agricultura, pecuária e pesca; (2) indústrias agroalimentares (IAA); (3) distribuição agrícola e alimentar; (4) comércio internacional; (5) consumidor; e (6) indústrias e serviços de apoio. O SAG é definido por Batalha (1997, p.30) como "o conjunto de atividades que concorrem para a produção de produtos agroindustriais, desde a produção dos insumos até a chegada do produto final ao consumidor". Dessa forma, um SAG específico é composto por empresas ou firmas entre as quais são realizadas várias transações. Existem diferentes sistemas agroindustriais dentro do agribusiness associados a diferentes produtos, bem como diferentes formas de organização.

O Complexo Agroalimentar e Agroindustrial (CAI) tem como ponto de partida uma determinada matéria-prima básica (café, algodão, leite, soja, uva). Essa matéria-prima pode originar diferentes produtos finais (queijo, nata, manteiga), formando várias cadeias de produção, cada uma delas associada a um produto final (BATALHA, 1997). A arquitetura de um CAI parte de uma matéria-prima principal que o originou, segundo os diferentes processos industriais e comerciais que ela pode sofrer até se transformar em diferentes produtos finais. A formação de um CAI exige a participação de um conjunto de cadeias de produção (CPA), cada uma delas associada a um produto ou família de produtos. Como as CPAs são as unidades básicas para os CAls, SAGs e demais formas de aglomerações produtivas agroalimentares e agroindustriais, elas serão abordadas com mais detalhes a seguir. 


\subsection{Cadeias Produtivas Agroalimentares e Agroindustriais (CPAs)}

Uma cadeia produtiva é formada pelo conjunto de componentes interativos, incluindo os segmentos produção agrícola, fornecedores de insumos e serviços, industriais de processamento e transformação, agentes de distribuição e comercialização, além de consumidores finais. $O$ objetivo é suprir o consumidor final de determinados produtos ou subprodutos (CASTRO, 1998).

A Cadeia Produtiva Agroalimentar e Agroindustrial (CPA) é definida a partir da identificação do produto final que, após identificado, é encadeado de jusante a montante pelas várias operações técnicas, comerciais e logísticas necessárias a sua produção (BATALHA, 1997). A CPA dos vinhos finos do Rio Grande do Sul pode ser um exemplo.

Conforme Batalha (1997), uma CPA pode ser segmentada, de jusante a montante, em três macro segmentos, que são:

a) Comercialização - É representada pelas empresas que mantém contato com o cliente final da cadeia de produção e que criam condições para o consumo e o comércio dos produtos finais (supermercados, restaurantes, cantinas, etc.), podendo, ainda, serem incluídas nesse segmento empresas que se responsabilizam pela logística de distribuição dos produtos acabados.

b) Industrialização - É constituída pelas empresas que transformam as matérias-primas em produtos acabados destinados ao consumo.

c) Produção de matéria-prima - É formado pelas firmas que fornecem matérias-primas iniciais para que outras empresas produzam o produto final destinado ao consumo.

Um SAG, um CAl ou uma CPA representam uma série de transações ( $T 1, T 2$, $\mathrm{T} 3, \mathrm{~T} 4, \mathrm{~T} 5)$, que interligam os diferentes segmentos, desde o setor de insumos, passando pela produção agropecuária, indústria (agroindústria e indústria de alimentos), distribuição (atacado e varejo), até a chegada do produto ao consumidor. Além disso, deve ser destacada a importância do ambiente institucional, que define as "regras do jogo", e do ambiente organizacional, que é o processo de ação coletiva das empresas, por exemplo, por meio de associações e/ou sindicatos. 
Esses conceitos foram introduzidos no Brasil, inicialmente, com a denominação de complexo agroindustrial, negócio agrícola e agronegócio e são definidos não apenas em relação ao que ocorre dentro dos limites das propriedades rurais, mas em todos os processos interligados que propiciam a oferta dos produtos da agricultura aos seus consumidores (ZYLBERSZTAJN; NEVES, 2000). Daí nasceu o conceito de cadeia produtiva, como subsistema (ou sistemas dentro de sistemas) do agronegócio, composto por muitas cadeias produtivas, ou subsistemas do negócio agrícola. As cadeias produtivas, por sua vez, possuem entre os seus componentes ou subsistemas os diversos sistemas produtivos agropecuários e agroflorestais (CASTRO et al., 1998). Essa generalidade do enfoque permite que se possa referir, de uma maneira geral, a um enfoque sistêmico em cadeias produtivas.

A mesoanálise tem sido definida como a análise estrutural e funcional dos subsistemas e de suas interfaces e interdependências dentro de um sistema produtivo integrado. Essas alterações são basicamente resultado do conjunto de cinco fatores: políticos, econômico-financeiros, tecnológicos, socioculturais e legais ou jurídicos.

Conceitualmente, uma cadeia produtiva é o encadeamento de atividades econômicas pelas quais passam e vão sendo transformados e transferidos os diversos insumos, incluindo desde as matérias-primas, máquinas e equipamentos, produtos intermediários e finais, sua distribuição e comercialização. Resulta de uma crescente divisão de trabalho, na qual cada agente ou conjunto de agentes especializa-se em etapas distintas do processo produtivo. Essas cadeias produtivas podem ser identificadas a partir da análise de relações interindustriais expressas em matrizes insumo-produto.

\subsection{Gestão de Sistemas e Cadeias Produtivas Agroalimentares e Agroindustriais}

De acordo com Castro (1998), a compreensão do funcionamento do agronegócio é essencial para a sua gestão. Esse conhecimento pode ser ampliado aplicando-se a lógica e as técnicas de análise de sistemas. A análise do agronegócio como sistema pode fornecer importantes subsídios para a formulação de macropolíticas e de estratégias de desenvolvimento setorial. Os resultados das 
análises de cadeias produtivas oferecem, no entanto, maiores oportunidades de aplicação, pela sua maior especificidade e possibilidade de aprofundamento, seja no plano do desenvolvimento setorial, na gestão e coordenação das cadeias ou na identificação de demandas tecnológicas para P\&D.

A análise de cadeias produtivas é uma ferramenta poderosa para investigar as várias interfaces que permeiam a dinâmica de um sistema agroalimentar e agroindustrial, pois a partir da premissa que o alimento ou uma matéria-prima energética deve ser produzido, industrializado e encaminhado até o consumidor final, qualquer disfunção em uma dessas etapas básicas compromete o abastecimento e a competitividade do sistema. Portanto, somente após a realização da análise dos aspectos tecnológicos, comerciais e logísticos de uma cadeia de produção agroindustrial, assim como dos fatores externos que a influenciam (socioeconômicos, legais e governamentais), é que poderão ser identificadas as disfunções e propiciar subsídios adequados à formulação e à implementação de uma política agroindustrial eficiente para o país, assim como tornar o sistema ou o segmento mais competitivo em nível internacional (BATALHA, 1997).

A competitividade de uma cadeia produtiva agroalimentar e agroindustrial é construída através da coordenação entre todos os seus agentes. Uma cadeia é composta pelas indústrias de suprimentos para a produção agropecuária, infraestrutura de transporte e a comunicação, a produção agropecuária, agroindústrias, indústria de alimentos, redes de distribuição e consumo e outros prestadores de serviços.

Para o estudo de competitividade, dentro de uma visão sistêmica de agronegócios, deve ser efetuado um corte vertical do sistema econômico. A análise de competitividade é realizada de forma integrada, com evidentes vantagens na coordenação, pois essa é resultante de importantes arranjos contratuais entre os vários agentes e atores. Essa análise sistêmica de competitividade de cadeias produtivas deve utilizar modelos teórico-metodológicos que facilite a identificação da estrutura das cadeias produtivas e dos fatores que afetam o desempenho de todo 0 sistema (BATALHA, 1997). Para isso, a análise sistêmica pode ser conceitualmente 
conduzida pelos princípios do Enfoque Sistêmico do Produto (CSA) e pela abordagem do Desenvolvimento Territorial Rural.

A representação de um sistema produtivo agroalimentar ou agroindustrial estruturado sobre uma cadeia produtiva constituí-se em uma importante ferramenta para o estudo ou identificação, por exemplo, de modificações ocorridas a montante (segmentos localizados "antes da porteira" ou fornecedores de insumos e serviços para agropecuária) e a jusante (segmentos localizados "depois da porteira" ou processadores e distribuidores da produção agropecuária) do processo de inovação original. De acordo com Batalha (1997), essa análise pode ainda avaliar as consequências das inovações como espaço analítico inicial (análise vertical), assim como junto a outras cadeias produtivas que se relacionem com ela (análise horizontal).

O crescimento econômico de uma região está associado ao desempenho de suas diversas cadeias produtivas. Frequentemente, variáveis de desenvolvimento social, como nível de emprego, saúde, habitação, também estão associadas ao desempenho de determinadas cadeias produtivas. Assim, o planejamento do desenvolvimento regional também é beneficiado pela base ampliada de informação gerada pelos resultados das análises prospectivas de cadeias.

\section{As aglomerações produtivas agroalimentares e agroindustriais dos territórios rurais}

A nova perspectiva sobre o mundo rural tem como base argumentos que abrem a possibilidade de o território rural também oferecer alternativas de emprego e renda e diversas outras formas de melhoria na qualidade de vida da população local. Entretanto, para oferecer isso, o território rural deve utilizar o seu potencial local, aproveitar as oportunidades externas e suas características históricas e culturais particulares e também estar integrado com a economia e a sociedade local. Esses são os contornos que poderão levar a uma nova ruralidade e contribuir para o desenvolvimento local dos territórios rurais. 
Essa transformação alterou profundamente a estrutura socioeconômica e cultural do "rural agrícola", com este deixando de ser exclusivamente agrícola para se tornar um conjunto fragmentado, diversificado e heterogêneo de territórios, formando uma complexa articulação de sistemas territoriais. Com isso, a agricultura deixa de ser o foco central da economia do território e as atividades produtivas agrícolas, industriais e de serviços passam a coexistir internamente e dividir esse papel.

As oportunidades externas estão, principalmente, nas possibilidades de acesso aos mercados agrícolas nacionais e internacionais. Desde a década de 1970, os SPLs ligados aos territórios rurais do sul do Brasil, onde a estrutura agrária é marcada pela agricultura familiar, vêm caminhando para uma crescente articulação e, em alguns casos, até para a integração socioeconômica, com o setor agroalimentar global, por intermédio de cadeias globais de produção e consumo.

Essa articulação e/ou integração tem sido o caminho seguido por alguns territórios, como resposta local às mudanças provocadas pela reestruturação do sistema produtivo global, ao modelo atual de modernização tecnológica dos processos produtivos agroindustriais e ao crescente acesso das famílias rurais aos diversos mercados locais (de trabalho, de bens e serviços e de fatores).

Muitos desses territórios rurais ainda se sustentam economicamente por meio de atividades de produção agropecuárias, nem sempre voltadas para produtos de melhor qualidade e/ou de maior valor agregado, ao lado de atividades agroindustriais, exercidas por pequenas e médias empresas, que procuram se manter em equilíbrio com o ambiente natural. Enfim, o desenvolvimento desses territórios depende tanto das dinâmicas externas, na maioria das vezes determinadas pelo processo de globalização, a partir dos mercados agrícolas ou agroindustriais, como também da capacidade dos seus agentes locais atraírem fluxos de recursos (capital para investimento produtivo, turistas ou trabalhadores capacitados) e dos seus "capitais territoriais": ambiental, cultural, social, institucional e o "saber-fazer".

Quando os territórios são rurais, os seus principais sistemas produtivos também podem ser caracterizados e/ou denominados de "Distritos Agrícolas", 
"Distritos Agroindustriais" ou "Sistemas Agroalimentares Localizados (SIALs)", com uma estrutura produtiva alicerçada nos "Sistemas Agroalimentares e Agroindustriais (SAGs)" e nas "Cadeias Produtivas Agroalimentares e Agroindustriais (CPAs)". Enquanto os dois primeiros foram estudados por economistas agrícolas italianos, a abordagem dos SIALs é uma proposição da escola francesa. Essas denominações variam de acordo com as suas tendências setoriais, na medida em que associam características dos setores industrial e de serviços, e com o grau de intensidade das relações socioeconômicas, institucionais e de proximidade. A seguir, demonstram-se as origens conceituais e teóricas dessas duas formas específicas de sistemas produtivos.

\subsection{Os distritos "agrícolas" e "agroindustriais" italianos}

$\mathrm{Na}$ década de 1970, economistas italianos iniciaram estudos sobre a importância da competitividade das empresas e dos processos de inovação, tendo como referência os conceitos de redes, meios inovadores e efeitos de proximidade, da teoria Marshalliana. Essa teoria foi resgatada por Beccattini (1994) para explicar o crescimento econômico de algumas concentrações industriais na Itália. Então, por meio do conceito de "distrito industrial", foi possível caracterizar as concentrações de pequenas empresas, onde as relações de proximidade e os efeitos derivados dessas relações serviam para promover o desenvolvimento local.

A mudança de foco das estruturas nacionais para as redes heterogêneas foi seguida pela "territorialização" do espaço rural, fazendo com que também alguns economistas agrícolas iniciassem um processo de adaptação da base conceitual do "distrito industrial", para a formação dos conceitos de "distrito agrícola" e "distrito agroindustrial". Esses termos surgiram para descrever os modelos organizacionais econômicos, típicos do sistema agroalimentar italiano, baseado em clusters de PMEs desse setor, regionalmente concentrados (CECCHI, 2001; BERTI, 2005). Segundo Brunore e Rossi (2007), essas formas de análise foram desenvolvidas para explicar a relevância dos sistemas econômicos regionais dentro do sistema agroindustrial italiano. 
Nos distritos agrícolas ou nos agroindustriais, destacam-se os relacionamentos entre a produção agrícola, as empresas industriais e de serviços (fornecedores, processadores e distribuidores) e o ambiente socioeconômico. Essa é a configuração teórica, muito semelhante aos conceitos e interpretações dos sistemas ou cadeias agroindustriais, de "agribusiness" ou de agronegócio. Essa abordagem interpretativa é formada por três fases, o "antes da porteira", os fornecedores para a agropecuária (ou agricultura), o "dentro da porteira", a produção agropecuária, e o "depois da porteira", as empresas agroindustriais e as distribuidoras do produto. Essa adaptação para "distrito agroindustrial" foi possível porque este guarda algumas características similares ao do "distrito industrial", tais como a concentração de pequenas e médias empresas (PMEs) e a estrutura organizacional muito parecidas, a predominância da produção de um bem típico, a concentração e a especialização de empresas, os relacionamentos inter-industriais facilitam o funcionamento do mercado local e, por fim, os relacionamentos pessoais que criam uma "atmosfera" favorável para as trocas de conhecimentos.

Porém, há uma diferença fundamental entre "distrito agrícola" e "distrito agroindustrial". O primeiro se forma a partir, apenas, do segmento da agropecuária (agricultura) e do segmento fornecedor de insumos, crédito, máquinas e equipamentos para esta. $\mathrm{O}$ "distrito agroindustrial" se forma a partir destes dois, mas também se inclui os segmentos que vêm "depois da porteira", o segmento que realiza o processamento do produto agrícola, a agroindústria e indústria de alimentos, e o segmento que faz a distribuição desse produto, o atacado e o varejo.

Para Cecchi (2001), o "distrito agrícola" é o interior territorial dos clusters em que a agricultura é a força que impulsiona as outras atividades do distrito, que só existem por causa da produção agrícola local. As características principais do "distrito agrícola" são similares às do "distrito agroindustrial" com relação ao realce da sua produção agrícola e da sua dependência em relação à indústria processadora, mas nos "distritos agroindustriais" a indústria processadora sempre está presente e com um alto percentual de processamento de produtos agrícolas vindo de fora do distrito. 
Os principais efeitos do processo de reestruturação produtiva mundial sobre os sistemas agroalimentares e agroindustriais são imigrações urbano-rurais, descentralização industrial, declínio da importância agrícola em termos econômicos e de ocupação, a diversificação da agricultura, a crescente importância do setor de serviços na geração de empregos e as mudanças nos modelos de consumo (BERTI, 2005). 


\subsection{Os Sistemas Agroalimentares Localizados (SIALs)}

Mais recentemente, sob um ponto de vista muito parecido com o dos italianos, Sautier (2002), Requier-Desjardins (2002b) e Muchnik (2002) propuseram a noção de Systèmes Agroalimentaires Localisès (SYAL), ou Sistema Agroalimentar Localizado (SIAL), em vez de simplesmente utilizar a noção de APL ou SPL do setor agroalimentar, porque os SIALs têm especificidades que os diferenciam significativamente dos outros SPLs. Conforme os autores, as principais especificidades dos SIALs são: o papel específico dos bens alimentares, por serem os únicos que são literalmente incorporados pelos consumidores no ato de consumo, em vez de serem somente "utilizados" como os demais bens de consumo; a especificidade da matéria-prima produzida, pois a atividade agroalimentar tem origem em uma matéria-prima agrícola, viva, heterogênea, sazonal e perecível; a relação com o ambiente e com a gestão dos recursos naturais; por fim, a vinculação frequente das atividades agroalimentares, mais do que outras atividades produtivas com uma parte significativa do "saber-fazer" local (intransferível) e com os conhecimentos transmitidos por aprendizagem.

Em quase todas as definições de SIAL, chama a atenção o destaque dado ao papel dos atores e/ou do capital social dentro desses sistemas. De acordo com Requier-Desjardins (1999), a definição de capital social reconhece tanto o seu componente social como o seu componente econômico. Assim, o capital social não se refere apenas às regras e normas empresariais e às relações de confiança e de amizade entre os indivíduos e as redes sociais, mas também às vantagens econômicas dos indivíduos obtidos a partir do capital social. Esse rendimento é gerado pela troca de informações, conhecimentos, mão de obra ou outras formas de cooperação.

Assim, nos SIALs, há uma relação muito próxima entre os modos de fabricação dos produtos e as preferências dos consumidores, com a produção e a economia rural centrada na transformação e na comercialização de produtos vindos, predominantemente, de unidades rurais familiares de pequena escala. Na definição de Requier-Desjardins (2002a e 2002b), o conjunto das relações sociais de trabalho 
e produção é o que constitui um SIAL. Essas relações possuem uma historicidade e uma especificidade que diferenciam esses sistemas produtivos locais (SPL), tanto em relação ao exterior como entre eles. Assim, procura-se mostrar que, nos SIALs, há uma relação muito próxima entre os modos de fabricação dos produtos e as preferências dos consumidores com a produção e a economia rural centrada na transformação e na comercialização de produtos, predominantemente vindos de unidades rurais familiares, com uma pequena escala produtiva e estruturados a partir de sistemas ou cadeias produtivas agroalimentares ou agroindustriais.

\section{Considerações finais}

Apresentou-se, neste texto, um emergente debate em torno da formação e do papel das aglomerações produtivas locais ou localizadas, que resultaram nas abordagens teóricas dos "Sistemas Produtivos Localizados (SPLs)" e, nos territórios rurais, a dos "Sistemas Agroalimentares Localizados (SIALs)". Com base nas conexões teóricas existentes entre a abordagem dos SIALs e os sistemas (SAGs) e cadeias produtivas (CPAs) agroalimentares e agroindustriais, presentes nos territórios rurais, é possível argumentar que estes últimos podem ser as principais estruturas produtivas dos SIALs. Essa conexão pode contribuir para fornecer algumas pistas para as questões do desenvolvimento rural e servir de base para políticas de desenvolvimento territorial-local, com base em sistemas e cadeias agroalimentares e agroindustriais mais ajustados ao perfil específico de cada território rural e de suas potencialidades locais.

Ampliaram-se os estudos sobre o papel das aglomerações produtivas, utilizando-se as abordagens dos SPLs e SIALs, porque essas são formas específicas de aglomerações produtivas, que podem atuar como mecanismos de mediação entre os efeitos da globalização e as propostas de desenvolvimento local dos territórios.

Nesse contexto, podem se formar novas dinâmicas de desenvolvimento localregional e, por isso, serão necessárias novas políticas públicas para essas dinâmicas territoriais formadas a partir de diversidades e potencialidades locais e 
das estratégias de desenvolvimento territorial. Com essas novas dinâmicas socioeconômicas de desenvolvimento dos territórios rurais e da maior integração dos setores econômicos agricultura-indústria-serviços, observa-se um processo de formação de aglomerações produtivas agroalimentares e agroindustriais nesses territórios rurais, nos quais o rural e o urbano são complementares em diversos aspectos. As aglomerações produtivas agroalimentares e agroindustriais têm como pilares a perspectiva territorial de desenvolvimento e as cadeias e sistemas produtivos localizados nos territórios rurais.

Nas análises de alguns aspectos teóricos relacionados à gestão de sistemas e cadeias produtivas agroalimentares e agroindustriais das estruturas produtivas básicas dos SIALs, foram utilizados alguns conceitos teóricos e abordagens que, cada vez mais, têm se mostrado adequados para estudar e compreender as estruturas e o funcionamento dos sistemas e cadeias agroalimentares e agroindustriais. Demonstraram-se algumas associações entre o desenvolvimento regional e o desempenho das cadeias produtivas locais e a importância do conhecimento sobre a estrutura e o funcionamento desses sistemas e cadeias agroalimentares e agroindustriais para o planejamento e a gestão do desenvolvimento regional-local. A importância da "coordenação" de um sistema ou cadeia agroalimentar ou agroindustrial está relacionada com a sua eficiência e competitividade. A competitividade é resultante da coordenação entre os agentes e atores e dos seus arranjos contratuais.

Os desafios externos, da globalização dos mercados e da competitividade têm sido superados através do desenvolvimento de abordagens "locais", "endógenas" e "territoriais", que enfatizam o potencial dos fatores locais e das ações dos atores sociais, das instituições e das aglomerações produtivas locais.

\section{Referências}

BATALHA, M. O. (Coord.). Gestão Agroindustrial. São Paulo: Atlas, 1997. v.1. 
BECATTINI, G. O Distrito Marshalliano. In: BENKO, G.; LIPIETZ, A. (Orgs.). As Regiões Ganhadoras-Distritos e Redes: os novos paradigmas da geografia econômica. Oeiras-Portugal: Celta Editora, 1994.

BENKO, G. Economia, Espaço e Globalização: na aurora do século XXI. São Paulo: Hucitec-Annablume, 2002.

BENKO, G.; LIPIETZ, A. O Novo Debate Regional. In: BENKO, G.; LIPIETZ, A. (Orgs.). As Regiões Ganhadoras-Distritos e Redes: os novos paradigmas da geografia econômica. São Paulo: Celta, 1994.

BERTI, G. II Distretto Rurale. Università Cattolica di Piacenza LEL, Quaderno n. 97, settembre 2005.

BONANNO, A. A globalização da economia e da sociedade: fordismo e pós-fordismo no setor agroalimentar. In: CAVALCANTI S, Josefa Salete Barbosa (Org.) Globalização, Trabalho, Meio Ambiente: mudanças socioeconômicas em regiões frutícolas para exportação. Recife: UFPE, 1999, p. 47-94.

BRUNORI, G.; ROSSI, A. Differentiating countryside: Social representations and governance patterns in rural areas with high social density: The case of Chianti, Italy. Journal of Rural Studies 23, 183-205. 2007.

CASSIOLATO, J. E.; LASTRES, H. M. O Enfoque em Sistemas Produtivos e Inovações Locais. In: FISCHER, Tania (Org.). Gestão do Desenvolvimento e Poderes Locais: marcos teóricos e avaliação. Salvador: Casa da Qualidade/PDGS, 2002.

CASTRO, A. M. G. et al. Prospecção de demandas tecnológicas de cadeias produtivas e sistemas naturais. Brasília: Embrapa/DPD, 1998.

CECCHI, C. Rural Development and Local Systems: The Case of the "Maremma Rural District". Tese (Doutorado - Department of City and Regional Planning) University of Wales. College of Cardiff, 2001.

CORREA, C. A. Analyse Comparative de 9 Cas D'Agro-Industrie Rurale de L'Amerique Latine. Université de Versailles - Saint Quentin en Yvelines: set. 2004.

MARSHALL, A. Princípios de Economia. São Paulo: Abril Cultural. 1992.

MORAES, J.L.A. Dinâmicas Sócio-Econômicas de Desenvolvimento dos Territórios Rurais: Os Sistemas Produtivos Localizados (SPLs) da Região Vale do Rio Pardo RS. Tese (Doutorado - Programa de Pós-Graduação em Desenvolvimento Rural PGDR) - Universidade Federal do Rio Grande do Sul, Porto Alegre, 2008.

MUCHNIK, J. Les Systèmes Agroalimentaires Localisés: intérêt, approche, interrogatios. Exposé Introductif - Colloque SYAL. Montpellier: GIS SYAL, 2002. 
MURDOCH, J. Networks - a new paradigm of rural development? Journal of Rural Studies, Amsterdam, n. 16. p.407-419. 2000.

POMMIER, P. Systemes Productifs Locaux. Montpellier: Colloque SYAL 2002.

REIS, José. Os Espaços da Indústria: a regulação econômica e o desenvolvimento local em Portugal. Porto: Afrontamento, 1992.

. Uma Epistemologia do Território. Instituto Superior de Economia e Gestão (ISEG). Lisboa: Universidade Técnica de Lisboa, 2006.

REQUIER-DESJARDINS, D. Agro-Industria Rural y Sistemas Agroalimentarios Localizados: Cuáles puestas? 1999. Disponível em: <http://www.prodar.org/cd.htm>. Acesso em: 30 julho/2006.

. Multifonctionnalité, territoire et secteur agro alimentaire: une approche par les "systèmes agroalimentaires localisés". Université de Versailles-Saint Quentin en Yvelines. CAHIERS DU C3ED, n. 2, v. 1, jun. 2002a.

. Les systèmes agroalimentaires localizes en américa latine: un facteur de compétitivité de l'agro-industrie rurale sur des marches globalizes? In: Économies et Sociétés, Série "Systèmes agroalimentaires", A. G., n. 25, 9-10, 2002b.

SABOURIN, E. Desenvolvimento territorial e abordagem territorial - conceitos, estratégias e atores. In: SABOURIN, E., TEIXEIRA, O. A. (Eds.). Planejamento e desenvolvimento dos territórios rurais - conceitos, controvérsias, experiências. Brasília: Embrapa Informação Tecnológica, 2002. p.21-37.

SAUTIER, D. Eléments de Perspective. Séance Pléničre Finale, Colloque SYAL. Montpellier: GIS SYAL, 2002.

WANDERLEY, M. N. B. A ruralidade no Brasil moderno; por um pacto social pelo desenvolvimento rural. In: GIARRACCA, Norma (Org.). ¿ Una nueva ruralidad en América Latina? Buenos Aires: CLACSO, 2001. p. 31-44.

ZYLBERSZTAJN D.; NEVES, M. F. (Orgs.). Economia e Gestão dos Negócios Agroalimentares. São Paulo: Pioneira, 2000. 